\title{
Representation Method of Warning Icons on Automobile Instrument Panel for Improving Driver's Cognitive Experience
}

\author{
Su-young Jung ${ }^{1}$ and Jong-hoon Choe ${ }^{2 *}$ \\ ${ }^{1}$ Ph. D Candidate, Dept. of Media Interaction Design, Ewha Womans University, \\ Seoul, Korea \\ ${ }^{2}$ Associate Professor, Dept. of Media Interaction Design, Ewha Womans \\ University, Seoul, Korea \\ ${ }^{1}$ suyoung@ewha.ac.kr, *2 deadant@ewha.ac.kr
}

\begin{abstract}
In recent years, automobile system and instrument panel are becoming increasingly intricate as they are equipped with varieties of functions and are being digitized. As a result, more warning icons have been created in the automobile. The dashboard for communication between the automobile and the driver provides the latter with diverse information necessary for driving through the warning icons on the instrument panel and also offers information on driver's status. According to a survey of 2,018 drivers from Britannia Rescue in July 2013, 98\% of drivers do not understand warning icons on the automobile instrument panel. Therefore, the meaning problems of the automobile warning icon were investigated to quickly identify the desired information and functions in a given situation and environment to the driver, and the representation method about warning icons on the automobile instrument panel was equally analyzed to improve the driver's cognitive experience.
\end{abstract}

Keywords: Automobile, Instrument Panel, Warning Icons, Cognitive Experiences, User Experience Design

\section{Introduction}

The communication between the automobile and the driver, which is the dashboard, provides the driver with data through a wide range of interfaces such as an instrument panel that is indicating diverse information necessary for driving, a steering wheel for changing direction of the automobile, and a center fascia with a control panel of audio or air conditioner. Furthermore, the information about speed, amount of fuel or emergency situation can be easily inspected by the automobile driver and could enjoy pleasure and comfort by adjusting the temperature of the room air or controlling the audio while driving. Through warning icons, drivers have a visual notification about the automobile condition, thus preventing the risk of accidents. However, there are many cases where the drivers do not recognize the warning icons.

According to a survey of British Schrader and TNS, international research company which was published in February 2014, it has been found that $42 \%$ of drivers could not accurately recognize the low-tire-pressure warning light on the instrument panel. [1]

The aim of this study is to research optimized user interface in the digital environment by looking at characteristics and factors about changing of the automobile interface by the digitalizing. Furthermore, this is intended to prepare the basis for predicting the change of interface in the near future.

Received (October 18, 2017), Review Result (January 5, 2018), Accepted (January 19, 2018)

* Corresponding Author 

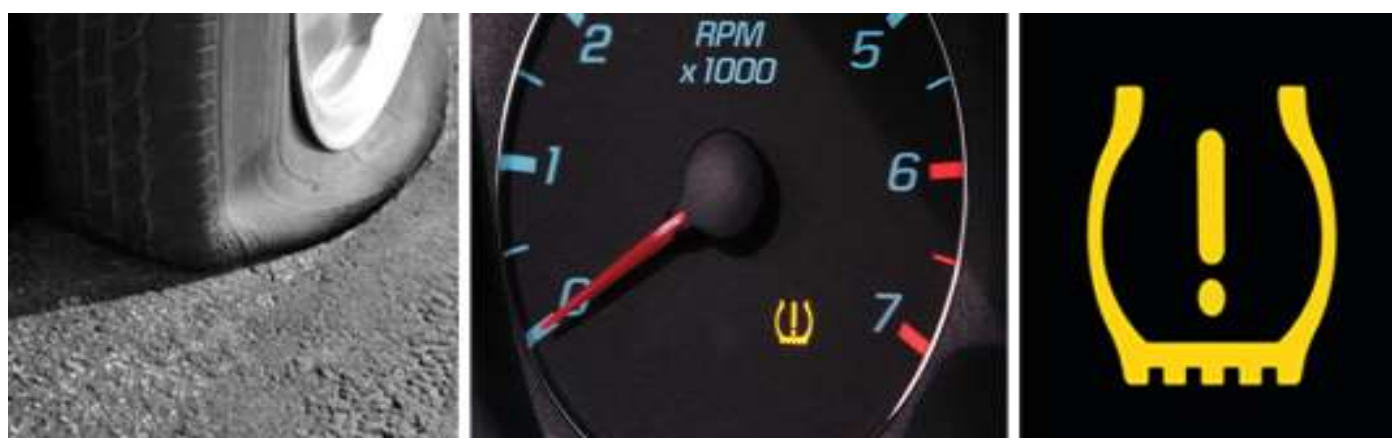

Figure 1. Low-Tire-Pressure Warning Light

In addition, Britannia Rescue investigated 99 warning lights in 15 of the UK's most popular automobiles and conducted a survey of 2,018 drivers in July 2013. As a result of survey responses, it has been shown that $98 \%$ of drivers do not understand warning icons on the automobile instrument panel. [2]

If the drivers do not recognize what the warning icons are, it can lead to a big accident. Therefore, it is a must for the driver to comprehend the warning icons since it is an essential signal that correctly informs the automobile condition. Moreover, the representation method and cognitive analysis of meaning delivery about automobile warning icon are necessary to quickly identify the desired information and functions in a given scenario and environment to the driver.

In this study, we studied design representation method to improve the cognitive experience for effective communication between the automobile and the driver after investigating the current state and problems of warning icons.

\section{Understanding the Instrument Panel}

\subsection{Information Display System of Automobile Instrument Panel}

One of the parts of the dashboard is the instrument panel with diverse mechanical devices on the front of the driver's seat, it is located on the front seat of the automobile and is composed of the following devices such as dashboard that is indicating various information necessary for driving, a steering wheel that can manipulate the direction of driving, and a center fascia that can be adjusted for the convenience of the driver and other passengers. To be particular about the components of the instrument panel, the instrument panel that provides the visual information necessary for driving includes a tachograph that specify the speed and distance of driving automobile as shown in [Figure 2], a tachometer that shows the number of engine RPM (Revolutions Per Minute), and a trip meter that indicates the mileage. In addition, it contains a fuel indicator, a coolant, a temperature indicator, and a warning light to notify the automobile condition to the driver depending on the situation [3]. 


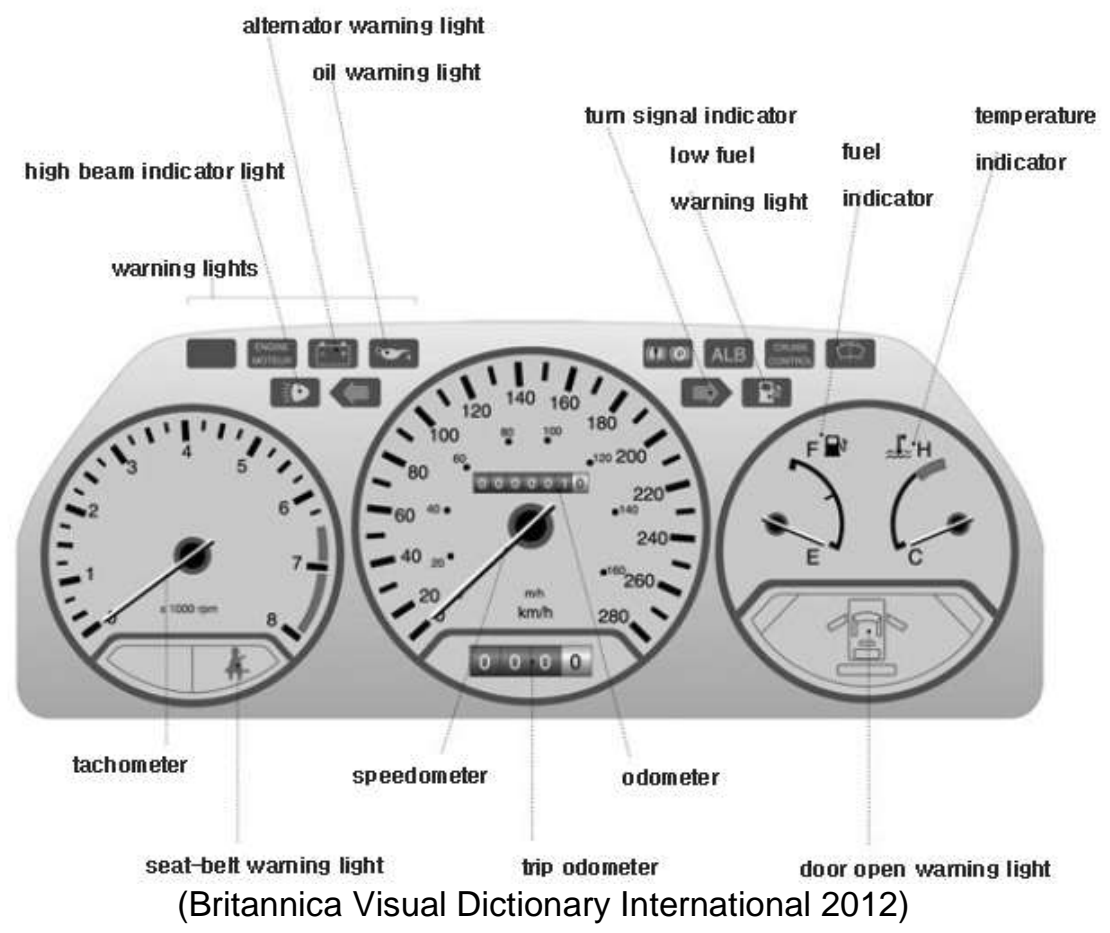

Figure 2. Instrument Panel

\subsection{Changes in Automobile Instrument Panel}

Recently, an automobile has been equipped with network functions and digitalized to provide safe and convenient driving information, such things used as an analog method in the cluster and center fascia have been replaced with displays. The Mercedes-Benz EClass that was launched in 2016 has two 12.3-inch displays on the instrument panel. Audi's TT and R8 have an LCD instrument panel with 3D maps and an OLED rear view mirror. [4]
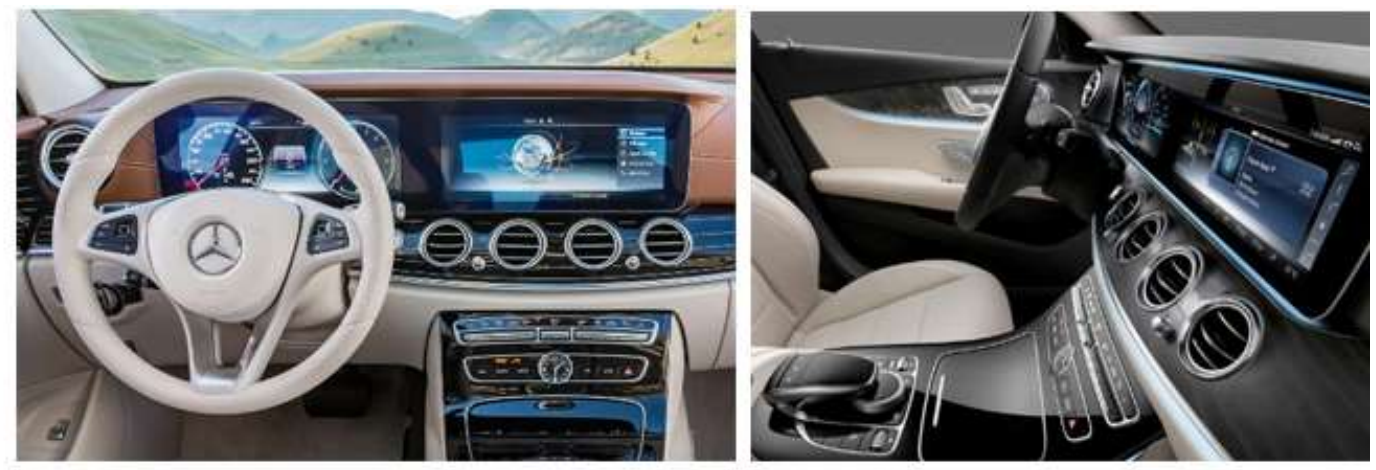

Figure 3. Benz New E-Class 

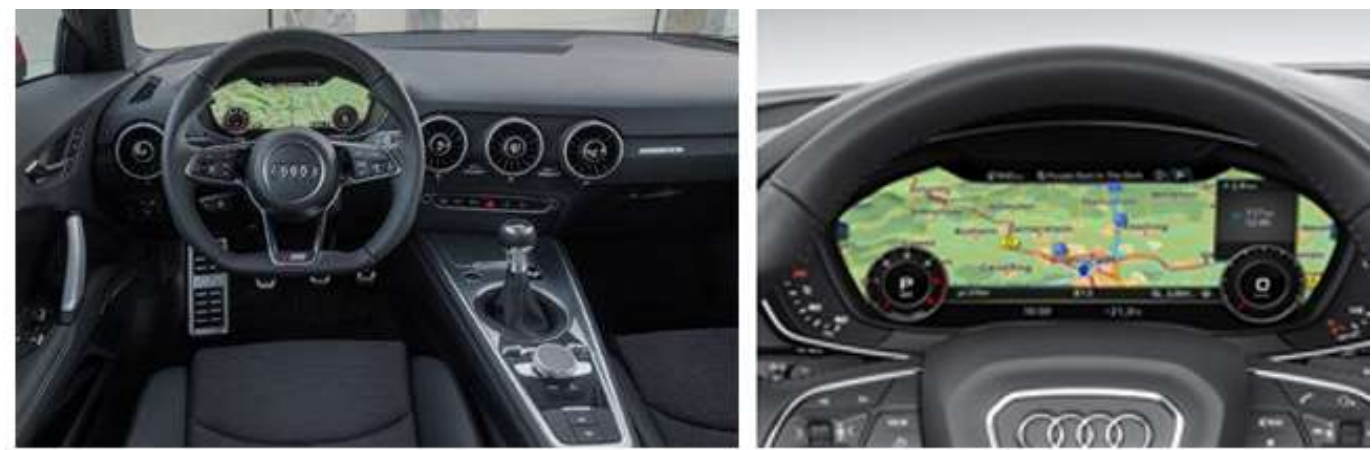

Figure 4. AUDI TT (2016)

The traditional analog method has been changing from the needle- like clock's hands to the digitalized ones and also modifying to be able to check out all the information of the automobile that the driver needs such as the navigation and the music list on the instrument panel.

As the driver's environment has been digitized and new functions have been increased, the meaning of the icons is indicated by visual icons as a means of information delivery and functionality execution for each function. Nevertheless, research has shown that digital instrument panels made for intuitive visual effects of many functions can make the driver uncomfortable. According to the results of "visual complexity analysis about instrument panel' published by the professor, Yonggu Ji (2016) research team of the information industrial engineering at Yonsei University, it has been shown that the complexity score of various instrument panels is as follows; digital instrument panel is 57.3, analog instrument panel is 50.5, and instrument panel with both analog and digital function is 46.1. (Ji, 2016) According to the J.D. Power '2015 Driver Interactive Vehicle Experience (Drive) Report', at least 20 percent of new automobile owners have never used 16 of the 33 technology features measured. (J.D. Power, 2015) [5] As such, it is imperative to study how to represent the information delivery in accordance with the driver's environment and the user's needs to recognize and use the diverse functions embraced by the digitization of the automobile.

\subsection{Automobile Warning Icons}

In recent years, as the latest technologies such as telematics, which connects a smartphone to automobile and autonomous vehicles, have been applied, the number of parts connected to automobile has been multiplied and functions have been diversified. By watching a wide range of warning icons and indicator lights on the instrument panel, the driver will be notified whether these functions are working properly or not. When getting in the automobile and starting an engine, a variety of lights on the instrument panel are turned on and off for a while.

If the drivers are clueless about the exact meaning of each icon, the risk of accidents increases because they are not aware of the automobile condition. Although these warning icons are rather different in the location of the information display and the icon design for each automobile manufacturer and each brand, since the rules that have been used for a long time are applied, all automobile manufacturers are based on that rules. 


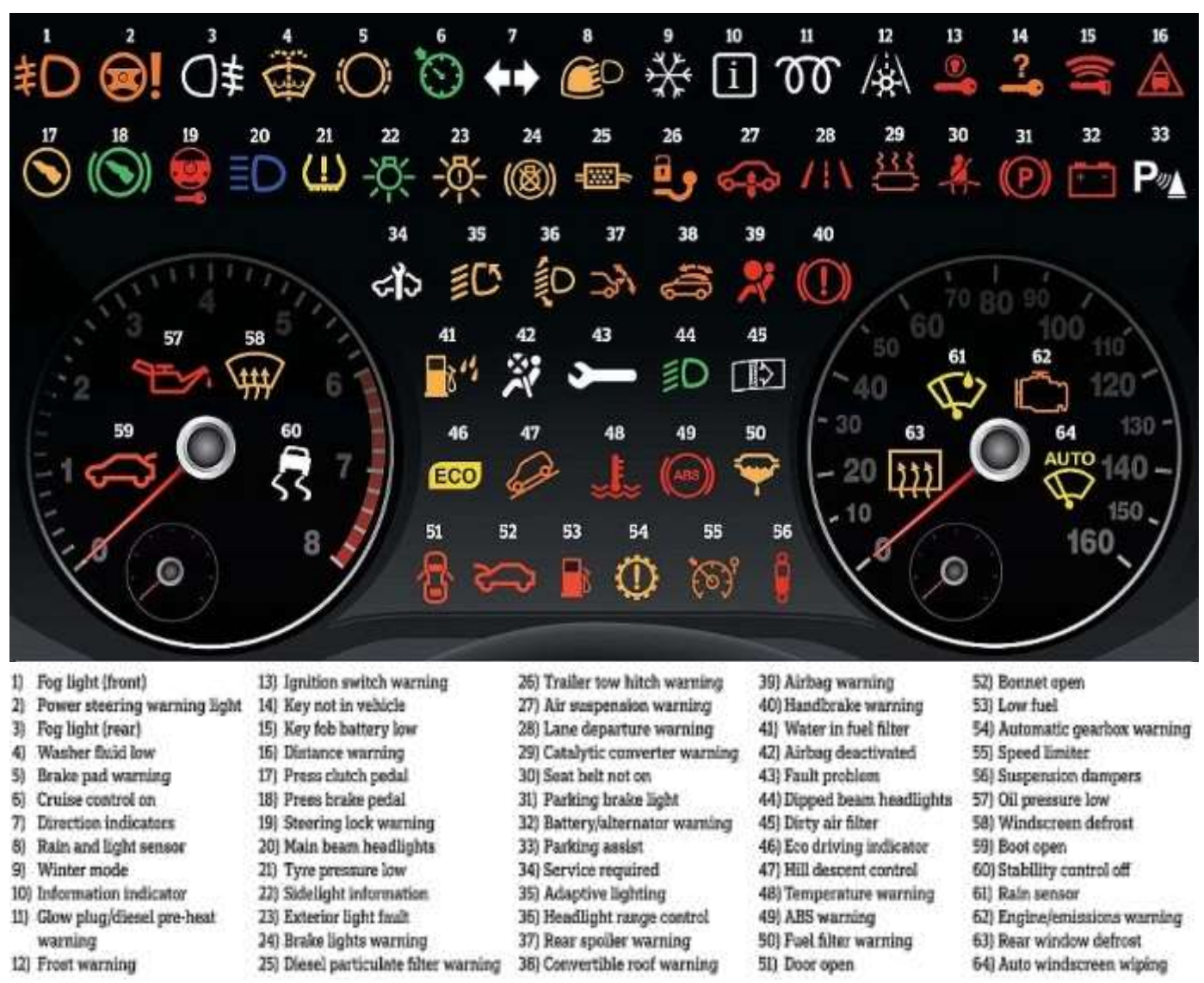

(ISO 2575:2010, www.iso.org)

\section{Figure 5. Warning Light Symbol (icon)}

[Figure 5] shows the 64 standard symbols based on international consensus at the ISO Technical Committee (ISO 2575, 2010). Automobile manufacturers should include the following international standard symbols for universal information symbols. In particular, it indicates risk criteria depending on color. A red warning light means that a problem with the highest risk that must be stopped and resolved immediately occurred.

A yellow warning light is a warning sign that it is not related to normal driving but it is a safety risk, drivers should be watched carefully. As blue or green light is a sign that indicates the operation status of the automobile, it also indicates the current performance status of the automobile, not the dangerous situation.

\section{Problems of Meaning Delivery on Automobile Warning Icon}

To indicate warning messages about the specific automobile condition, automobile warning lights were classified in the form of icons. Among them, warning icons displayed on the instrument panel indicate the operating condition or malfunction of the automobile parts or software.

However, it is difficult for the driver to understand what warning message is since it is not easy to understand the meaning of the warning light itself. In case of the warning lights of the newly created functions, they are not applied by the law or standard rule. For this reason, it is hard for drivers to understand the exact meaning of these warning lights due to the automobile manufacturer's own representation.

Aside from driving defensively, tire air pressure is one of the most important factors in making automobile the safer and more efficient. Tire Pressure Monitoring Systems is designed to help drivers be aware of tires that do not contain sufficient air, and according 
to a survey of UK Schrader and TNS, international Research Company indicated in the introduction above, most of the drivers did not exactly recognize the air pressure warning light icon.

Furthermore, according to a survey of Britannia Rescue in July 2013, it has been shown that $98 \%$ of drivers are puzzled about the warning icons on the automobile instrument panel. Among them, $95 \%$ of drivers had incorrectly identified the catalytic converter warning, and $86 \%$ of drivers mistakenly named the air conditioning light, followed by a tire pressure warning that flummoxed $71 \%$. Furthermore, $48 \%$ of drivers did not even recognize the brake warning light and 35\% did not understand an airbag alert, along with $27 \%$ mistaking it for a seat-belt warning. (See Table 1) [2]

Table1. Survey Results on Warning Icon Understanding (* Britannia Rescue)

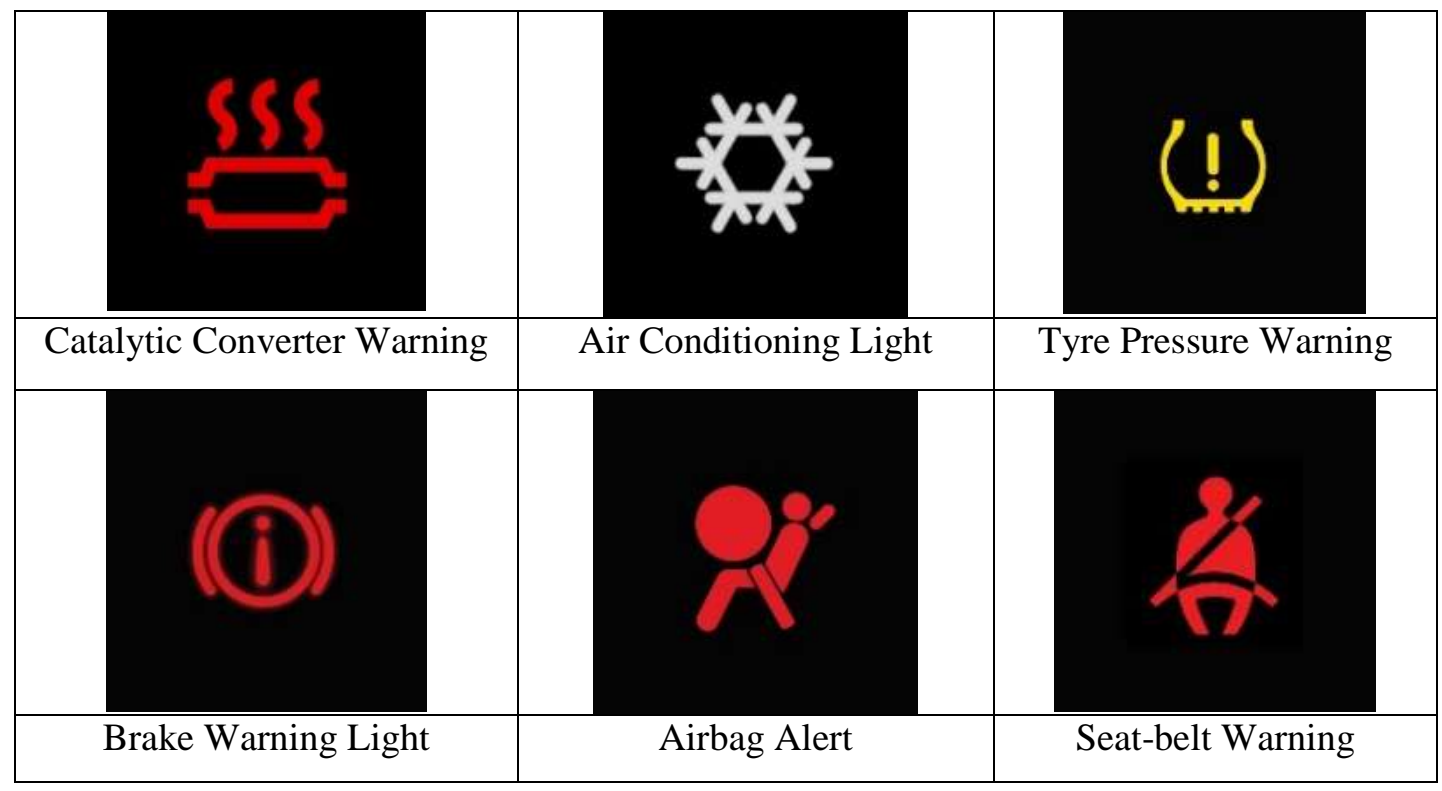

As shown in [Table 5], it is troublesome for the drivers to understand the interpretation because three warning icons do not indicate the exact meaning visually - for instance, a catalytic converter warning, a tire pressure warning, and a brake warning that a majority of drivers had difficulty understanding the meaning among six representative icons that the users do not understand or recognize. Especially, as catalytic converter warning is an anti-pollution device, it appears when the exhaust system cannot properly filter out harmful substances from the human body. Most of the users are unable to recognize the corresponding icon since the meaning is also difficult to understand.

According to an analysis of CarMD, a leading provider of automobile diagnostic information in 2016, it has been found that drivers felt that their automobile had mysterious symptoms after they did not understand the warning icons and went to an automobile repair shop, but there were many cases where they paid for expensive repair services. (CarMD,2016) Among them, the rate of failure cause related to catalytic converter warning icon has been increasing and repair costs are also high. The problem is also serious because four out of six icons the driver does not recognize is the most dangerous red color that must be stopped and resolved immediately.

Manual explains the warning icons in the automobile but does not state any comprehensive information about the cause of lighting related to warning lights and its solution.

Therefore, most of the drivers are clueless on how to figure out the problem when they watch the lighting of warning lights. There is no consistency in lighting situation owing to the fact that the number and position of warning lights are different from each automobile manufacturer and brand. [6] The position of the warning light may vary since each 
automobile manufacturer has its own design and the design of the instrument panel is different. The shape or representation method of the icon should be unified so that users can quickly recognize it.

\section{Warning Icon for Improving Driver's Cognitive Experience}

We studied three icons with high risk that are included in the standard symbols among the six icons that are hard to be recognized or hard to be understood by the driver, as the survey results of Britannia Rescue mentioned above to study how to represent the warning icon of automobile instrument panel to improve the driver's cognitive experience. As the air conditioning icon is a general icon that indicates the operating status of the air conditioning system, it was excluded because it is not included in the standard symbols but only in some automobiles.

As survey results of the Web Survey in 2007, the visual elements among sense of sight, sense of hearing, sense of touch, and sense of smell in the automobile accounted for $40 \%$ as the most important sense. The sense of sight is the majority of the senses that drivers use while driving. The most efficient information delivery device is a visual device, and visual information is also transmitted with sound.

Icons are proportional to awareness when visual function and design components have similarities. That is, a design that is visually well represented about functionality can improve user's awareness. [7]

Rudolf Arnheim emphasized the importance of movement by saying "Movement is a strong, visual perception object." in his book "Art and Visual Perception(1954). Furthermore, it proved that if the subject of representation has movement, it can attract public gaze and draw the attention, and it is also useful for information delivery. [8]

As Donald Norman, a cognitive psychologist argued "adjusting the momentary experience is a detail.", if simple motions are given to icons using micro-interaction, it can be an effective way of attracting and drawing the attention of users. Micro Interaction is an icon that informs the current state of the system. It is a design that provides detailed feedback to the users at the time of using the product and is a concept that allows users to recognize and induce behavior by indicating icons or giving a small motion. Currently, it has been used as a communication tool to provide feedback, alarm, and guide to users on the web or mobile devices.

Therefore, the researcher proposed the design as representation method by simple motion through the shape of the visually cognitive icon and the micro- interaction method.

Table 2. Suggestion on How to Represent Warning Icon Design

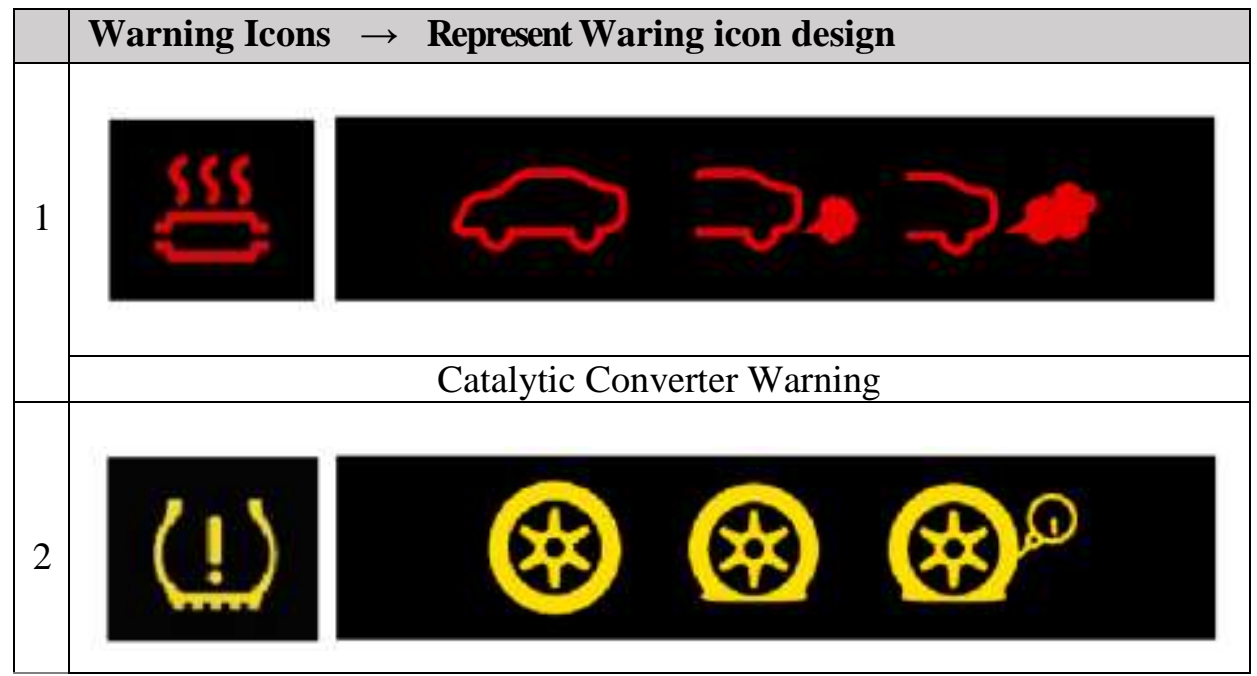




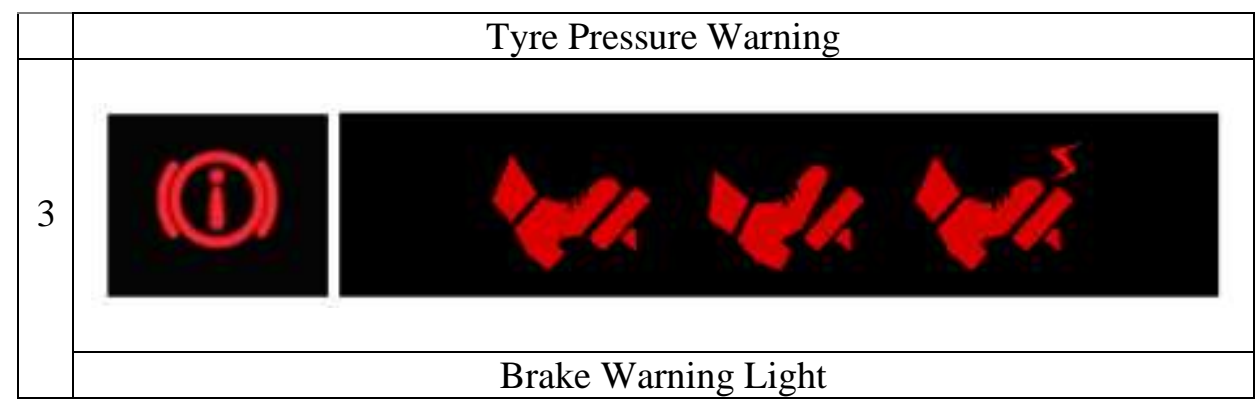

The Catalytic Converter Warning icon, which $95 \%$ of the drivers do not understand represents a device that harmlessly reduces harmful exhaust gases by the catalyst in the middle of the exhaust pipe. Although the current icon shape visually indicates the shape of the catalytic converter, it is hard to understand because most of the users do not know the shape of the catalytic converter. Like No. 1 as shown in [Table 2], a visual representation of the exhaust gas from the automobile muffler allows users to easily recognize its function. The tire air pressure icon which is closely related to safety is represented by embodying the appearance of getting flat tires since the proper air pressure must be maintained through periodic check-up. In addition, as the most important factor in driving automobile is braking, the brake warning light on the parking brake intuitively represented the driver's braking behavior.
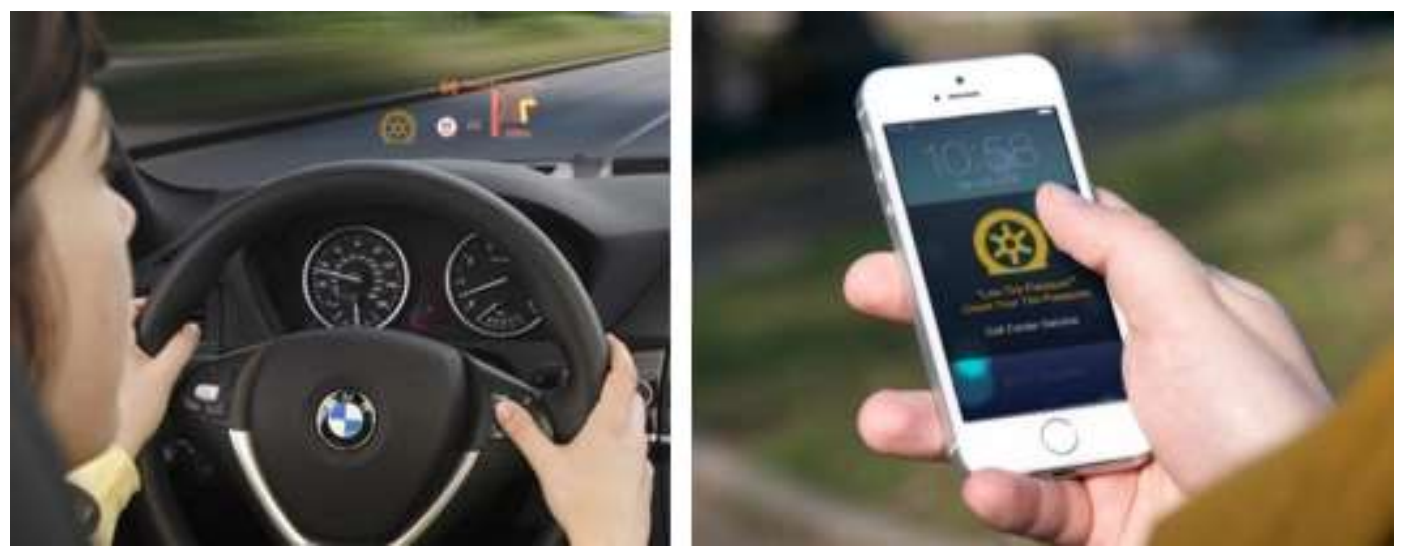

Figure 6. Notification Service with Smartphone

As shown in [Figure 6], drivers can recognize and manage the automobile condition more accurately before getting in an automobile by interworking the automobile and the smartphone.

In addition, as mentioned above, if the driver is notified through the visual icon, motion, and sound, it will be more effective for improving the cognitive experience because visual information delivery is accompanied by information delivery through a sense of hearing.

\section{Conclusion and Suggestion}

In recent years, the majority of automobiles use complicated systems that created instrument panel to become increasingly complex, and they are equipped with various safety and convenience devices. As a result, additional icons are getting included in the automobile. The users always would like to know their state based on "The system should always keep users informed about what is going on" in Jakob Nielsen's (1994) Usability Heuristics. The automobile provides information to drivers through the icons on the instrument panel and also informs them of its condition itself. However, most of the 
drivers are clueless about the information that appears on their automobile instrument panel.

In this study, the problem of warning icon was investigated, which is an important factor that informs the driver of the automobile condition from the dashboard for communication between the automobile and the driver, and proposed the research and design of the icon representation method for the driver to recognize faster and improve usability. The representation method of the proposed design can be a solution process that can narrow the distance between the driver and the automobile rather than one correct answer. [9]

As automobile technology has been progressed and services have been increased, usercentered interface design for each situation should be studied based on basic usability and design.

\section{Acknowledgments}

This paper is a revised and expanded version of a paper entitled 'Study on the Warning Icons on Automobile Instrument Panel for Improving Driver's Cognitive Experience' presented at the 5th International Conference on Interdisciplinary Research Theory and Technology (IRTT 2017), Daejeon, Korea, 21-23 December 2017.

\section{References}

[1] P. Wise, "Discovers 42 Percent of Drivers Still Can't Identify Lifesaving Dashboard Warning Symbol”, Schrader International, Inc, (2014).

[2] MailOnline, http://www.dailymail.co.uk/news/article-2381805/Warning-ahead-98-cent-driversunderstand-dashboard-lights.html, (2013).

[3] E. Lee, "A Study on the Instrument Panel of Automobile depending on Gestalttheorie", MA thesis, Kookmin University, (2011), pp.16-33.

[4] S.Y. Jung and J.H. Choe, "Research on Change of Automobile User Interface Design by Digitalizing", Asia Pacific Journal Modeling and Simulation for Mechanical System designed and Analysis, vol. 1, no. 1, (2016), pp.41-46

[5] JD Power, "2015-driver-interactive-vehicle-experience-drive-report", JD Power Report, (2015).

[6] B. Choi, "A Research of Information Structure and Information Layout in Vehicle Display based on Information Property", Ph.D thesis, Ewha Womans University, (2017), pp.59-65.

[7] C.H. Chang, "A Study on Efficiency Communication for transform an Icon a Perceptible for On-Line Environment", MA thesis, Hanyang University, (2007), pp. 36-65.

[8] H.Y. Ham, "A Study on the Visual Sense Effect of Movement of Motion Graphic", MA thesis, ChungAng University, (2004), pp. 25-67

[9] S.Y. Jung and J.H. Choe, "Study on the Warning Icons on Automobile Instrument Panel for Improving Driver's Cognitive Experience", International Journal of Engineering \& Technology for Automobile Security, vol. 1, no. 2, (2017), pp. 7-12

[10] S.Y. Jung and J.H. Choe, "Design Changes in Automobile Interface for Drivers Due to the Spread of Smart Media", Information Journal, vol.20, no.9(B), (2017).

[11] D. Norman, "Emotional Design”, Perseus Books Group, (2005).

[12] R. Arnheim, "Art and Visual Perception: A Psychology of the Creative Eye", University of California Press, (1954).

[13] S.Y. Jung and J.H. Choe, "Application of Emotional Video Contents Using Car Windows", Jour. of KoCon. a, vol.14, no.4, (2014), pp.37-46.

[14] “NEGROPONTE”, N, Being Digital, RandomHouse, (1994).

[15] S Murphy, A Nafaa and J. Serafinski, “Advanced Service Delivery to the Connected Car", International Workshop on internet of Things Communications and Technologies, (2013), pp. 158-164.

[16] A. K. Dey and G. D. Abowd, "Toward a better understanding of context and contextawareness", Technical Report GIT-GVU-99-22, College of Computing, Georgia Institute of Technology, (1999).

[17] Business Wire, http://www.businesswire.com/. news/home/20140409005428/en/National-Survey-Schrader\%C2\%AE-Discovers-42-Percent-Drivers, (2014).

[18] Teamfiat, http://www.teamfiat.com/threads/do-you-understand-your-car-dashboard.10323/, (2006). 
International Journal of Control and Automation

Vol. 11, No. 1 (2018) 